\title{
Modified Geopolymer-based Wood Adhesive using Waterborne Polyurethane
}

\author{
Dawei Pan, ${ }^{\mathrm{a}, \mathrm{b}}$ Hanzhou Ye, ${ }^{\mathrm{a}, \mathrm{b}}$ Xiaoqian Wang, ${ }^{\mathrm{a}, \mathrm{b}}$ and Yang Zhang a,b,*
}

Geopolymer binders show great potential in the application of eco-friendly wood composite adhesives. The applicability of organic-inorganic hybridreinforced geopolymer composites as plywood binder was investigated. In this study, a geopolymer-based wood adhesive was fabricated by mixing a matrix-geopolymeric slurry; a toughening agent, waterborne polyurethane; and a silane coupling agent, that served as the covalent "bridge" between the waterborne polyurethane with a geopolymer matrix. The results showed that the waterborne polyurethane exhibited excellent compatibility with the geopolymer and served as a flexibilizer, which transformed the matrix from a microfractured structure to a denser morphology. Moreover, the shear strength of bonded plywood and the morphology of the fracture surface after the tensile measurement were measured. The resulting geopolymer/wood interface was well bonded, and the interfacial bonding strength was higher than the wood strength matrix after modification. The introduction of waterborne polyurethane and silane coupling agent improved the water resistance of the composites and increased the wet shear strength of plywood from $0 \mathrm{MPa}$ to $0.35 \mathrm{MPa}$. Notably, a weak wood/alkali interface was formed under alkaline conditions due to the strong diffusion of alkali metal ions between the interfaces.

Keywords: Wood adhesive; Geopolymer; Waterborne polyurethane; Bonding interface

Contact information: a: Beijing Key Laboratory of Wood Science and Engineering, Beijing Forestry University, Beijing 100083, China; b: Ministry of Education Key Laboratory of Wooden Material Science and Application, Beijing Forestry University, Beijing 100083, China;

*Corresponding author: bjfuzhangyang@bjfu.edu.cn

\section{INTRODUCTION}

Geopolymers are an emerging class of eco-friendly, cementitious material, characterized by low carbon dioxide emissions, exceptional mechanical properties, superior fire resistance, and excellent durability (Atis et al. 2015; Law et al. 2015; Mucsi et al. 2017; Pasupathy et al. 2017). Thus, geopolymers are pertinent to a wide range of applications - particularly reinforcement, building, and bonding materials (Latella et al. 2006; Zhang et al. 2014; Duan et al. 2016), in addition to numerous other industries. In recent years, the development of geopolymers used as formaldehyde-free adhesives has shown extraordinary potential to produce wood-based composites (Sarmin et al. 2014; Shalbafan et al. 2016; Bahrami et al. 2019). However, recent investigations into the application of geopolymers in the wood adhesive industry (Gouny et al. 2012; Shalbafan et al. 2016, 2017) determined that their bonding capacity is insufficient for gluing wood; primarily due to the geopolymer network's extreme brittleness and low interfacial compatibility (Alomayri et al. 2015; Sá Ribeiro et al. 2016). Furthermore, because the raw wood material inherently dry shrinks and swells in response to hot and humid conditions, 
peeling or even cracking between the wood unit and the artificial board's adhesive is likely, which seriously impacts the product's performance and appearance. Therefore, any adhesive appropriate for wood-based panel production must have characteristics suitable for the wood unit's dimensional changes-i.e., sufficient toughness. The practical application of geopolymer-based adhesives is limited in the wood-based panel industry and more research is needed in this area (Shalbafan et al. 2016). Thus, geopolymer adhesive molecular structures must be strengthened to develop high-performance wood adhesives.

Physically or chemically modifying geopolymers has potential to expand the range of their potential applications, because the modified geopolymers can exhibit superior physicochemical properties in comparison to those of their parent. Utilizing composite properties via the physical blending method is an effective option for improving geopolymers' strength and toughness. Numerous previous studies have described the synthesis, characterization, and properties of organic and inorganic fiber reinforced geopolymers (Nematollahi et al. 2015; Kroehong et al. 2018; Mucsi et al. 2018; Ye et al. 2018). Inorganic-organic hybrid modification technology, which intertwines two or more polymer networks, is particularly notable. Using this method, it is possible to achieve interpenetration, while maintaining the original characteristics of each polymer, thus obtaining a comprehensive performance superior to that of either polymer individually (Imai et al. 2000; Wen et al. 2014; Sethi et al. 2017). As such, current research focuses on introducing a variety of organics into geopolymers and implementing organic-inorganic hybrid modification techniques to overcome geopolymer brittleness ( $\mathrm{Li}$ et al. 2013; Du et al. 2016). However, to date, previous studies have not reported a complete, in-depth explanation of brittle geopolymers' toughening and strengthening mechanism, nor have they fully explored the geopolymer/wood interface bonding process. These conceptual gaps may result in limited improvement of the resulting material's bonding performance.

Waterborne polyurethane (WPU) is a synthetic elastomer with its specific chemical structure that offers outstanding performance; thus its chemical and mechanical properties have attracted significant attention (Kuan et al. 2005; Lee et al. 2019). In addition, silane coupling agent's siloxy groups are reactive with inorganic substances (geopolymer) after hydrolysis and its organic functional groups are reactive or compatible with organic substances. As a result, the coupling agent promotes interfacial fusion and enhances performance by hydrolyzing to form a bond between the organic and inorganic substrates.

The objective of this work was to investigate the formation of an organic-inorganic hybrid geopolymer-based wood adhesive by adding WPU assisted with silane coupling agent, and ultimately to use those observations to propose an interface bonding mechanism and identify the structure between the wood and geopolymer matrix. From the results of this study, the authors established the complex physicochemical relationships between the geopolymer, WPU, and silane coupling agent interfaces, which will provide scientific basis and methodology for the design of geopolymer-toughening modification techniques. Thus, the information contained herein is crucial for the development and application of ecofriendly, high-performing, geopolymer-based wood composites.

\section{EXPERIMENTAL}

\section{Materials}

Commercial metakaolin (MK) was utilized as the aluminosilicate source of the geopolymer-based adhesive matrix and was purchased from Hangzhou Junyi New Material 
Technology Co., Ltd. (Hangzhou, China). The MK chemical composition was analyzed via X-ray fluorescence (XRF-1800; SHIMADZU, Tokyo, Japan), and the results are provided in Table 1. A sodium silicate solution composed of $14.7 \% \mathrm{Na}_{2} \mathrm{O}$ and $28.7 \% \mathrm{SiO}_{2}$ served as the geopolymerization activator and was purchased from Wuxi Yateks Joint Chemical Industry Co., Ltd. (Wuxi, China). The silane coupling agent ( $\gamma$-Aminopropyl triethoxysilane, kh-550) was obtained from Nanjing Chuangshi Chemical Co., Ltd. (Nanjing, China); while the WPU was procured from Dongguan Qiancheng Plastic Raw Materials Co., Ltd. (Dongguan, China) with a solid content of $56.4 \%$. The $250 \mathrm{~mm} \times 250$ $\mathrm{mm} \times 1.5 \mathrm{~mm}$ poplar (Populus $\times$ canadensis 'Neva') veneer with an $8 \%$ moisture content was obtained by rotary cutting from Hebei Province, China.

Table 1. Chemical Compositions of MK

\begin{tabular}{|c|c|c|c|c|c|c|c|c|c|c|}
\hline Component & $\mathrm{SiO}_{2}$ & $\mathrm{Al}_{2} \mathrm{O}_{3}$ & $\mathrm{TiO}_{2}$ & $\mathrm{Fe}_{2} \mathrm{O}_{3}$ & $\mathrm{Na}_{2} \mathrm{O}$ & $\mathrm{K}_{2} \mathrm{O}$ & $\mathrm{MgO}$ & $\mathrm{P}_{2} \mathrm{O}_{5}$ & $\mathrm{SO}_{3}$ & $\mathrm{~V}_{2} \mathrm{O}_{5}$ \\
\hline wt\% & 51.16 & 45.82 & 1.72 & 0.525 & 0.184 & 0.177 & 0.100 & 0.072 & 0.043 & 0.040 \\
\hline
\end{tabular}

\section{Methods}

Fabrication of organic-inorganic hybrid geopolymer $(\mathrm{HG})$

The HG was prepared using the following procedure. To begin, pure geopolymers (PG) were synthesized by mechanically mixing MK and an alkaline activator solution (1:1.8 of weight content) for $120 \mathrm{~s}$. The solid content of the resulting PG was $63.81 \%$. Next, different concentrations of WPU ( $0 \mathrm{wt} \%, 2 \mathrm{wt} \%, 4 \mathrm{wt} \%, 6 \mathrm{wt} \%$, or $10 \mathrm{wt} \%)$ were mixed with the obtained PG, resulting in five samples with differing WPU wt\%. Silane coupling agent in the amount of $1.5 \mathrm{wt} \%$ was then added to each sample. The organicinorganic HG was obtained after stirring the samples for $90 \mathrm{~s}$. The geopolymer-based wood adhesive component ratios are listed in Table 2.

Table 2. Experimental Formulations of the Geopolymer-based Adhesives

\begin{tabular}{|c|c|c|c|c|}
\hline Sample Code & MK $(\mathrm{g})$ & WPU $(\mathrm{g})$ & $\mathrm{kh}-550(\mathrm{~g})$ & Activator $(\mathrm{g})$ \\
\hline PG & 100 & 0 & 0 & 180 \\
\hline HG-0 & 100 & 0 & 4.2 & 180 \\
\hline HG-2 & 100 & 5.6 & 4.2 & 180 \\
\hline HG-4 & 100 & 11.2 & 4.2 & 180 \\
\hline HG-6 & 100 & 16.8 & 4.2 & 180 \\
\hline HG-10 & 100 & 28 & 4.2 & 180 \\
\hline
\end{tabular}

$X$-ray diffraction $(X R D)$

The XRD patterns of PG and HGs were determined with a Bruker D8 ADVANCE $\mathrm{X}$-ray diffractometer (Bruker, Karlsruhe, Germany), using $\mathrm{Cu} \mathrm{K \alpha}$ radiation $(\lambda=1.5406 \AA$ ). The incidence angle was varied from $10^{\circ}$ to $80^{\circ}$ at a scanning rate of $2^{\circ} / \mathrm{min}$. The samples were ground into a powder (200 mesh) and dried at $50{ }^{\circ} \mathrm{C}$ in an oven to dryness before testing.

\section{Fourier transform infrared (FTIR) spectroscopy}

The dry samples (PG and $\mathrm{HGs}$ ) were fully milled with $\mathrm{KBr}$ and compressed before being scanned with FTIR spectrometer (Nicolet 6700; Thermo Scientific, Waltham, MA, USA) in a spectral range of 4000 to $400 \mathrm{~cm}^{-1}$ at a $4 \mathrm{~cm}^{-1}$ resolution. The samples were ground into a powder (200 mesh) and dried in $50^{\circ} \mathrm{C}$ oven to dryness before testing. 
Scanning electron microscopy with energy dispersive X-ray spectroscopy (SEM/EDS)

The composite specimens' fracture surface cross-sectional morphologies were imaged with a SEM microanalyzer (Quanta FEG 250; FEI Company, Eindhoven, Netherlands). The microstructure of the geopolymer/wood composites interface were analyzed via SEM/EDS.

\section{Mechanical tests}

The bonded samples' shear adhesive strength was measured according to the China National Standard GB/T 17657 (2013). First, the poplar veneer samples were glued with the geopolymer-based adhesives using a $250 \mathrm{~g} / \mathrm{m}^{2}$ spreading rate for each layer. Next, three poplar veneers, with two coated layers, were pressed under a static pressure and temperature of $1.2 \mathrm{MPa}$ and $130{ }^{\circ} \mathrm{C}$ for $300 \mathrm{~s}$. The pressing process was carried out using a laboratory press (Xinxieli 100T, Suzhou New Cooperation Group Co., Ltd, Jiangsu, China). The test specimens were cut into $100 \mathrm{~mm} \times 25 \mathrm{~mm}$ rectangles, and the shear adhesive strength was measured using an MMW-50 mechanical testing machine (Jinan Resistance Test Machine Co., Ltd., Shandong, China) at a speed of $5 \mathrm{~mm} / \mathrm{min}$. In addition, the wood breaking rate was tested simultaneously. The glued samples' shear adhesive strength was determined under dry and wet conditions. The wet samples were tested after being immersed in $63{ }^{\circ} \mathrm{C}$ water for $3 \mathrm{~h}$. All the tests were replicated at least 12 times and the average was reported.

\section{RESULTS AND DISCUSSION}

\section{XRD Analysis}

An XRD measurement is an effective strategy for characterizing organic-inorganic hybrid composites. Figure 1 shows the crystalline regions of PG and HGs with various contents of WPU.

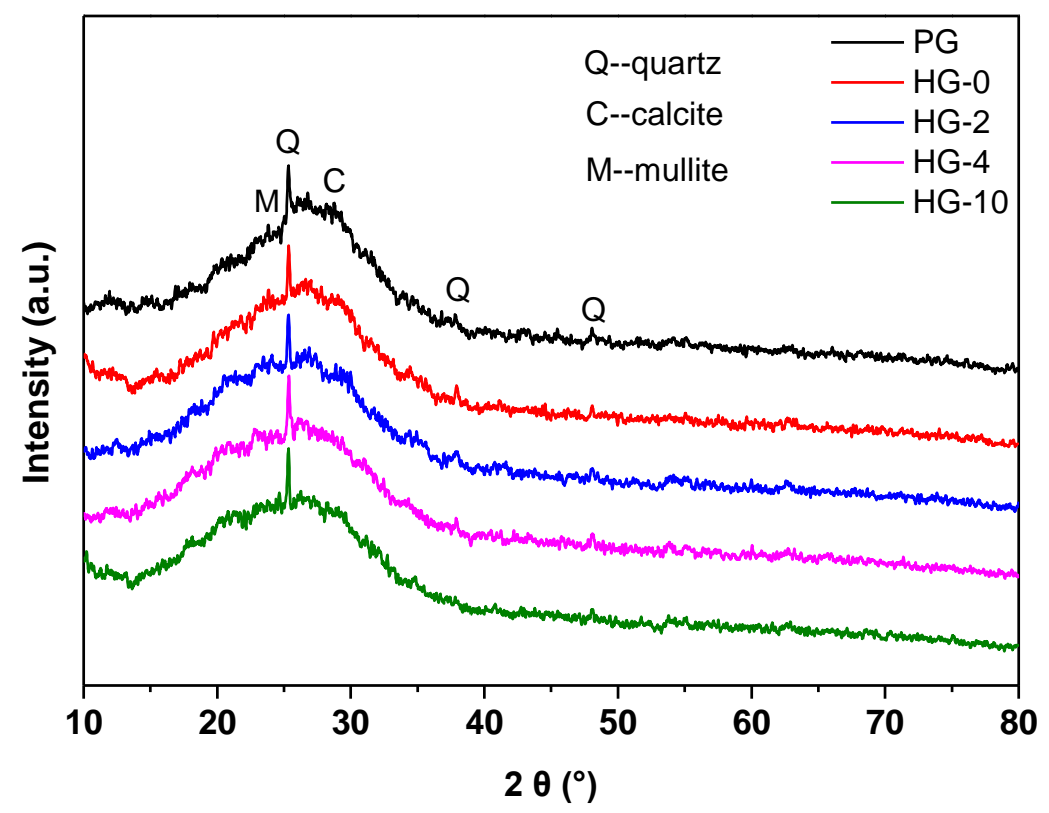

Fig. 1. XRD patterns of $P G$ and $H G$ composites 
The main activated products of geopolymer composites are generally amorphous with a certain amount of impurities such as unreacted quartz (Zhang et al. 2015). Calcite and muscovite were clearly recognized in all composites. Amorphous diffraction peaks appeared at $15^{\circ} 2 \theta$ to $40^{\circ} 2 \theta$, as can be seen for all XRD patterns, due to the typical amorphous phases of geopolymer composites (Zhang et al. 2014). This played a fundamental role in the geopolymer characterization, reflecting the adhesion properties of the geopolymers. Overall, as determined by the increase in WPU content, it resulted in little influence in the hydration products of the geopolymer composites, which remained predominantly amorphous.

\section{FTIR Analysis}

The FTIR was employed to examine the effect of the WPU and kh-550 on the geopolymer structure and chemical/functional groups. The results are depicted in Fig. 2. With respect to the WPU composites, the broad peak at $3394 \mathrm{~cm}^{-1}$ is attributed to $\mathrm{N}-\mathrm{H}$ stretching and the hydroxyl groups' O-H stretching vibration (Wang et al. 2004). The signals in the 2931 to $2863 \mathrm{~cm}^{-1}$ wavenumber range are due to the $-\mathrm{CH}_{2}$ - groups' symmetric and asymmetric stretching, while the peaks at $1716 \mathrm{~cm}^{-1}$ and $1541 \mathrm{~cm}^{-1}$ are attributed to $\mathrm{C}=\mathrm{O}$ stretching vibration and $\mathrm{N}-\mathrm{H}$ bending vibration, respectively (Ghosh et al. 2016). For the PG, the broad band around $3500 \mathrm{~cm}^{-1}$ and $1651 \mathrm{~cm}^{-1}$ is assigned to $\mathrm{O}-\mathrm{H}$ stretching and bending, respectively (Le Troëdec et al. 2009; Gouny et al. 2012; Gharzouni et al. 2016). Another strong band was centered at $1019 \mathrm{~cm}^{-1}$, due to the $\mathrm{Si}-\mathrm{O}-\mathrm{Si}$ or $\mathrm{Si}-\mathrm{O}-\mathrm{Al}$ vibration bands in the geopolymer (Ye et al. 2018). After interacting with the kh-550, the double peaks at $2854 \mathrm{~cm}^{-1}$ and $2928 \mathrm{~cm}^{-1}$, which correspond to the symmetric and asymmetric vibration of the $-\mathrm{CH}_{2}$ - groups, respectively, appeared in the HG-0 sample; this was assigned to the silane coupling agent's alkyl chain's moiety (Wang et al. 2012).
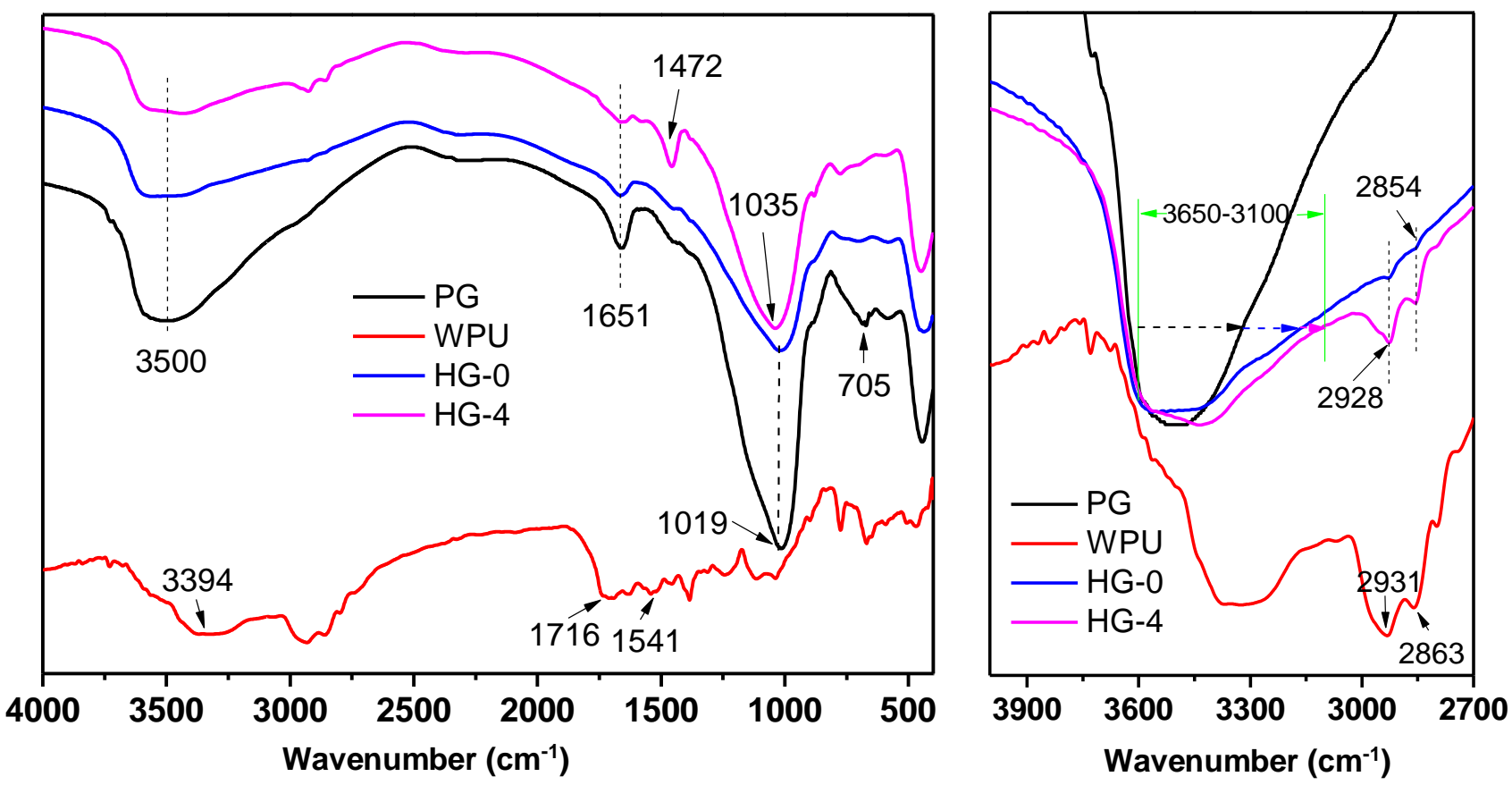

Fig. 2. FTIR spectra of WPU, PG, HG-0, and HG-4 for different wavenumber regions 
Regarding the hybrid composites, in both the HG-0 and HG-4 samples, the broad bands located at approximately $3500 \mathrm{~cm}^{-1}$ corresponded to the free and bound $-\mathrm{OH}$ and $\mathrm{N}$ $\mathrm{H}$ bending vibrations. In particular, the broad absorption peak ( 3650 to $3100 \mathrm{~cm}^{-1}$ ) centered at $3500 \mathrm{~cm}^{-1}$ became broader in comparison to the PG specimen, potentially because the suspended groups $(-\mathrm{OH},-\mathrm{NH}-$, or $-\mathrm{COOH})$ on the WPU/kh-550 chains generated intermolecular combinations with the Si-O-Al framework on the PG. In addition, the chemical composition of WPU in HG-4 composites were represented in the peaks at 1472 $\mathrm{cm}^{-1}$, corresponding the $\mathrm{CH}_{3}$ asymmetric deformation vibrations or $\mathrm{CH}_{2}$ scissor vibrations. Hybrid composite absorption changes were not clearly observable throughout the wide range of 1400 to $900 \mathrm{~cm}^{-1}$, which is likely due to the strong absorption overlap of the Si$\mathrm{O}-\mathrm{Si}$ or $\mathrm{Si}-\mathrm{O}-\mathrm{Al}$ geopolymer vibration in this region. Finally, a shifting of the $\mathrm{Si}-\mathrm{O}-\mathrm{Si}$ or Si-O-Al vibration was observed from $1019 \mathrm{~cm}^{-1}$ to $1035 \mathrm{~cm}^{-1}$, after WPU was incorporated into the geopolymer matrix. Additionally, the bands at around $705 \mathrm{~cm}^{-1}$ that are associated with Si-O-Al vibrations evidently decreased (Barbosa and MacKenzie 2003).

\section{Geopolymer-based Wood Adhesive Microstructure Characterization}

As shown in Fig. 3, SEM measurements were performed to characterize the geopolymerization of the hybrid geopolymer-based composites.
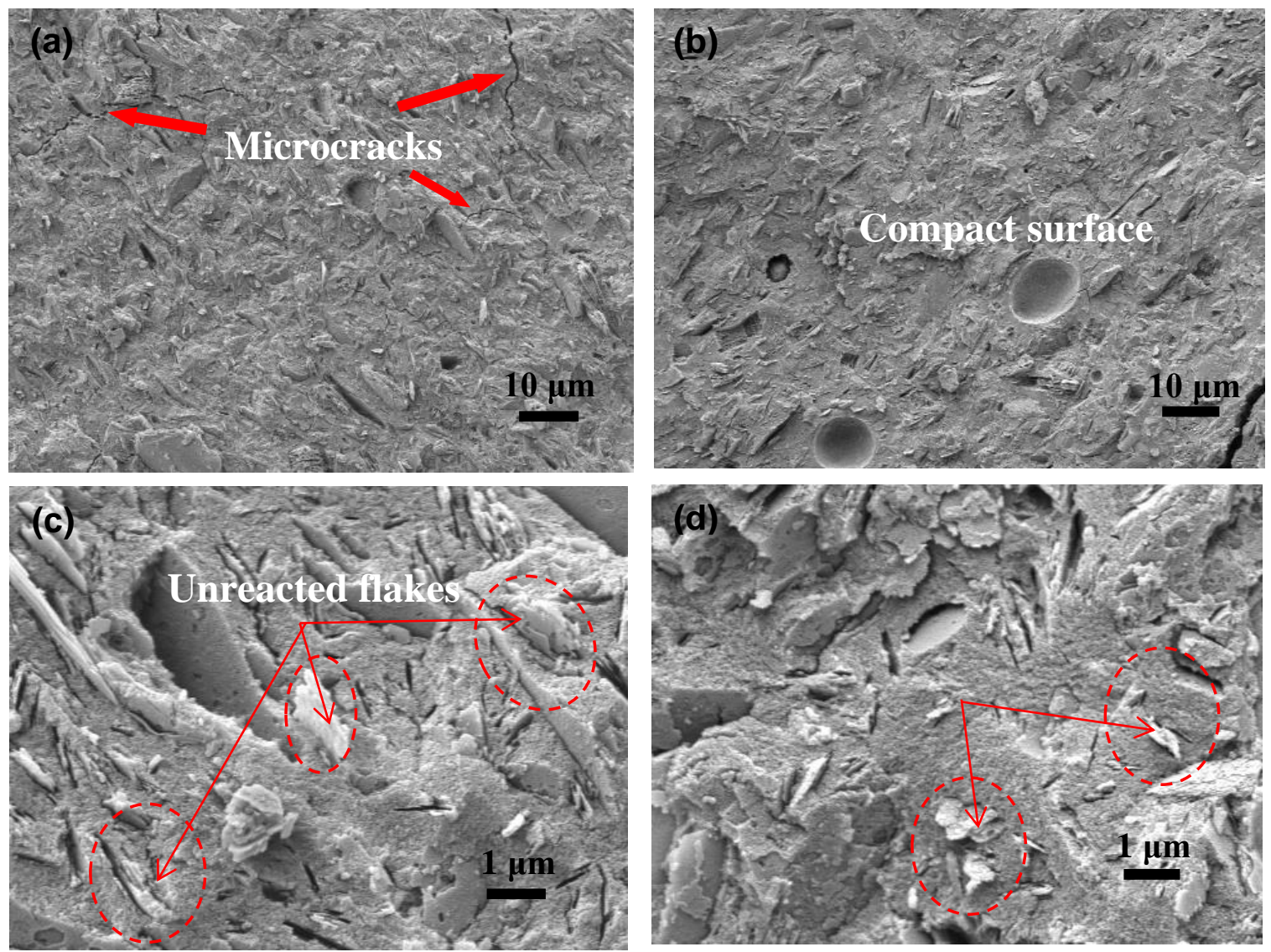

Fig. 3. The fracture surface SEM images of (a and c) PG and (b and d) HG-4

For the PG specimen (Fig. 3a), noticeable microcracks were observed on the micrographs of the geopolymer matrix. In contrast, a more compact and smoother surface was observed on the hybrid composite specimens (Fig. 3b), indicating excellent 
compatibility of organic polymers with inorganic substrates. This phenomenon was attributed to the fact that the WPU was evenly distributed in the geopolymer's gel phase. Because the organic polymer provides a more cohesive microstructure, with a reduced amount of microcracks (Colangelo et al. 2013), it forms an interpenetrating network structure with the geopolymer. In addition, bridging and chemical bonding between the silane coupling agent and the geopolymer effectively prevent the generation and development of microcracks, resulting in the geopolymer acquiring superior toughness. Furthermore, higher magnification images showed that less plate-shaped voids, from remnant and partially reacted MK, were left over in the HG-4 sample (Fig. 3d) (Duxson et al. 2005; Bell et al. 2009) compared to the PG specimen (Fig. 3c). This phenomenon is likely the result of unreacted flakes being partially dissolved by the WPU dispersion emulsion and/or the WPU, thus promoting effective continuation of geopolymerization with its water-holding action in an inorganic matrix system. The water-holding leads to a higher degree of geopolymerization, as the interaction between the WPU polar groups with the water molecules delays their evaporation.

\section{SEM/EDS Analysis}

As shown in Figs. 4 and 5, the SEM/EDS measurements were performed to analyze the geopolymer/wood interface construction. The results showed a distinct mechanical interlocking structure between the geopolymer-based adhesive with the wood matrix. Furthermore, the three images in Fig. 6 depict the distribution and diffusion patterns of aluminum, silicon, and sodium.

The three elements' extension thicknesses, as measured by the nanomeasurer, were $\mathrm{Si}=56.5 \mu \mathrm{m}, \mathrm{Al}=56.7 \mu \mathrm{m}$, and $\mathrm{Na}=71.1 \mu \mathrm{m}$. Thus, the sodium was most prone to infiltration into the geopolymer/wood interface. A plausible explanation for this result is that when the adhesive was applied to the wood, the adhesive's alkali component, which originates from the sodium silicate, preferentially penetrated the wood's surface with moisture, forming a subtle alkali-wood layer. In order to further verify the presence of an alkali-wood layer, the wood fracture surface was examined by FTIR, as shown in Fig. 5.

The alkali-wood layer's emerging peak at $1735 \mathrm{~cm}^{-1}$ was attributed to $\mathrm{C}=\mathrm{O}$ vibration of esters, ketones, and aldehydes ( $\mathrm{Gu}$ et al. 2013). Moreover, another new absorption peak was detected at $1235 \mathrm{~cm}^{-1}$, which represents $\mathrm{C}-\mathrm{O}-\mathrm{C}$ stretching in lignin phenol-ether bonds (Lehto et al. 2018). Both results indicated alkali-wood layer formation in the geopolymer/wood interface. In this study, the geopolymer-based wood adhesive was an aluminosilicate binder formed by alkaline activation of precursor materials at a high temperature of $130{ }^{\circ} \mathrm{C}$, resulting in a strongly alkaline environment in the whole bonding process from solid alumina- and silica-containing precursor to the end of the geopolymerization (Zhang et al. 2014). As a result, in this layer, dissolution of the wood's polar components and hemicellulose degradation were promoted under hot pressing conditions, while the extracts contaminated the wood's surface. This is one of the primary reasons the wood bonding was blocked. As precipitate formed, it became a weak interfacial layer, resulting in premature structural damage during the shear test, as shown by the browner failure surface in Fig. 5. Thus, as described above, the geopolymer/wood interface was roughly divided into three parts, namely a geopolymer matrix, alkali-wood layer, and a wood matrix (Fig. 4). 


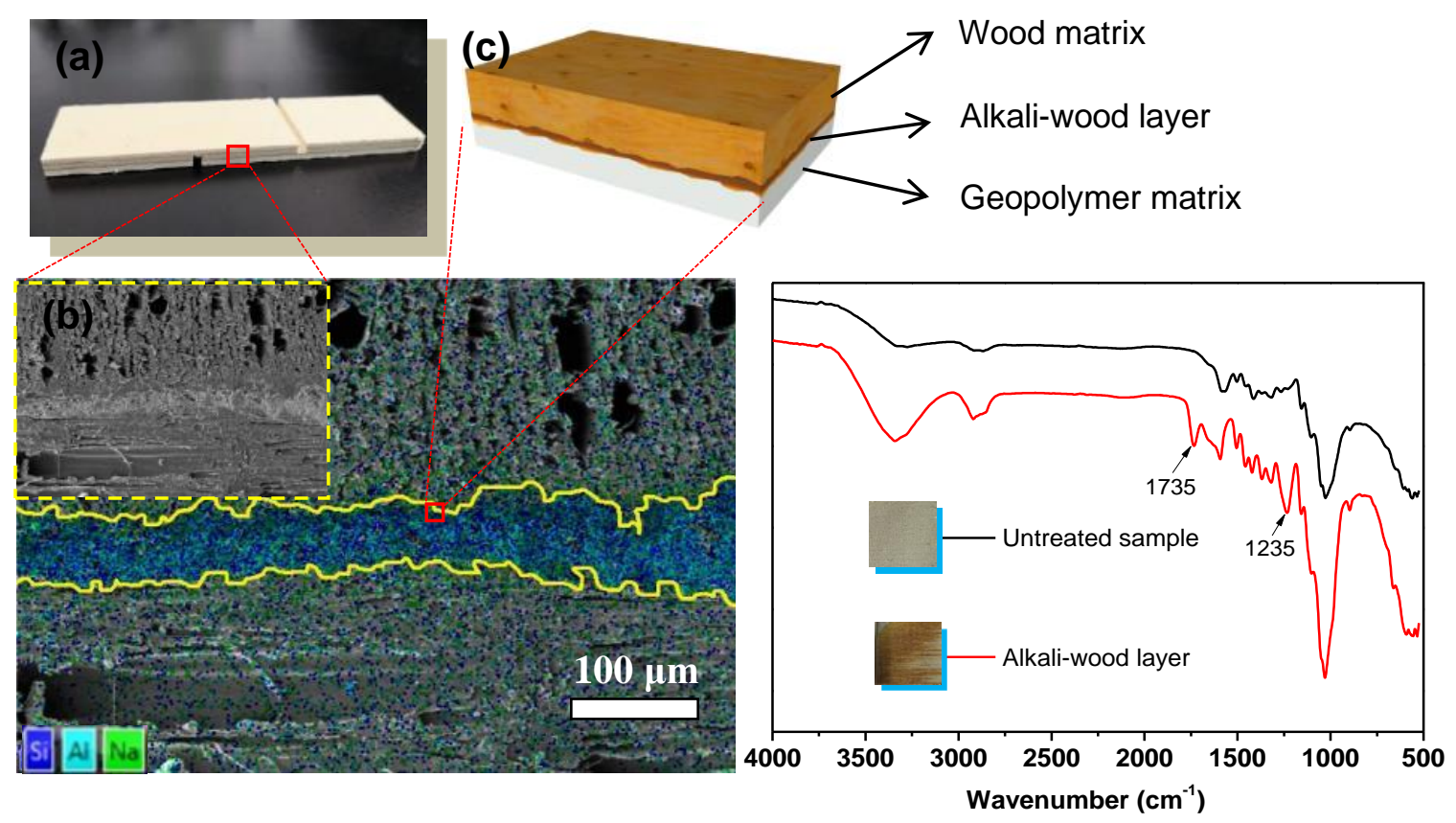

Fig. 4. The glued sample (a), SEM/EDS images of bonding interface (b), and its schematic illustration
Fig. 5. FTIR spectra of untreated sample and alkali-wood layer
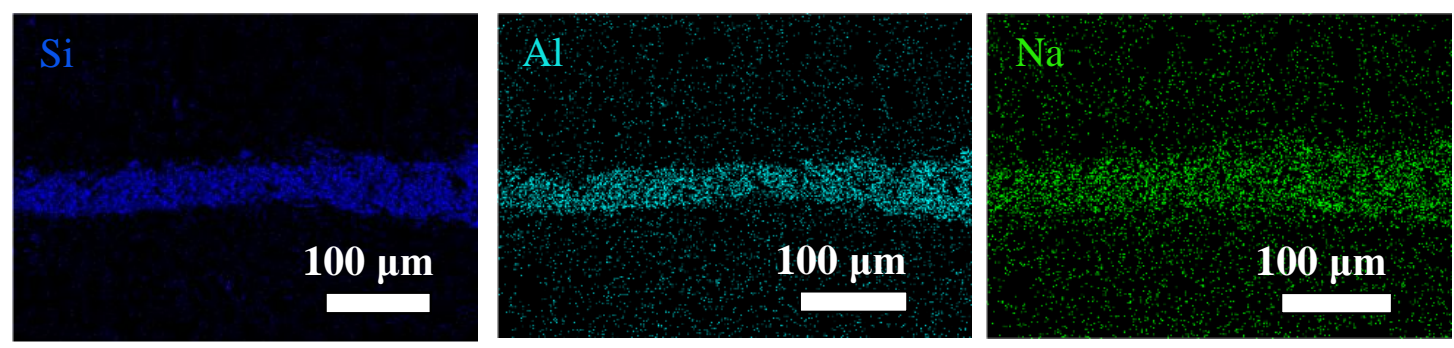

Fig. 6. Si, $\mathrm{Al}$, and $\mathrm{Na}$ element distribution of the EDS scanned interface

\section{Shear Strength}

The dry and wet shear strength test was used to investigate the effect of WPU on the geopolymer-based composites' adhesion properties. As shown in Fig. 7a, pristine PG presented the lowest adhesion strength and wood failure ratio (WFR), indicating poor bonding performance and water-resistance. Consistently, the addition of WPU/kh-550 into the PG system induced noticeable improvement in the adhesion performance, with a dry shear strength (DS) that reached 1.69 MPa and WFR approaching 100\%. This indicated that under dry conditions, the interface failure was in the wood matrix. Interestingly, after incorporating WPU, the PG system exhibited a wet shear strength reaching $0.35 \mathrm{MPa}$, indicating that $\mathrm{HG}$ composites reacted with active hydrogen-containing groups $(-\mathrm{OH}$, $\mathrm{NH}_{2}$, $-\mathrm{COOH}$, etc.) in the wood to form a chemical bond, resulting in improved bonding performance and water-resistance. The enhancement mechanisms of WPU and Kh-550 in geopolymer system was shown in Fig. 7b.

To further analyze the morphology of the plywood fracture surface, SEM measurements were performed to determine the types of adhesive failures after dry shear 
testing. Figure 8 shows a smooth fracture surface in the plywood samples prepared with PG adhesive, indicating a weak alkali-wood interfacial layer failure, which is consistent with the SEM/EDS results. After the introduction of WPU/kh-550 into PG matrix, the HG samples showed a rougher wood fracture surface with many pulling fibers. These results indicated that incorporation of WPU/kh-550 not only promoted the HG to wood sizeadaptability, but also improved the adhesive surface attachment. The addition of highly elastic WPU benefited adhesive distribution and osmosis during the plywood hot press process, thus forming a stronger mechanical interlock with wood and giving rise to enhanced adhesion properties.
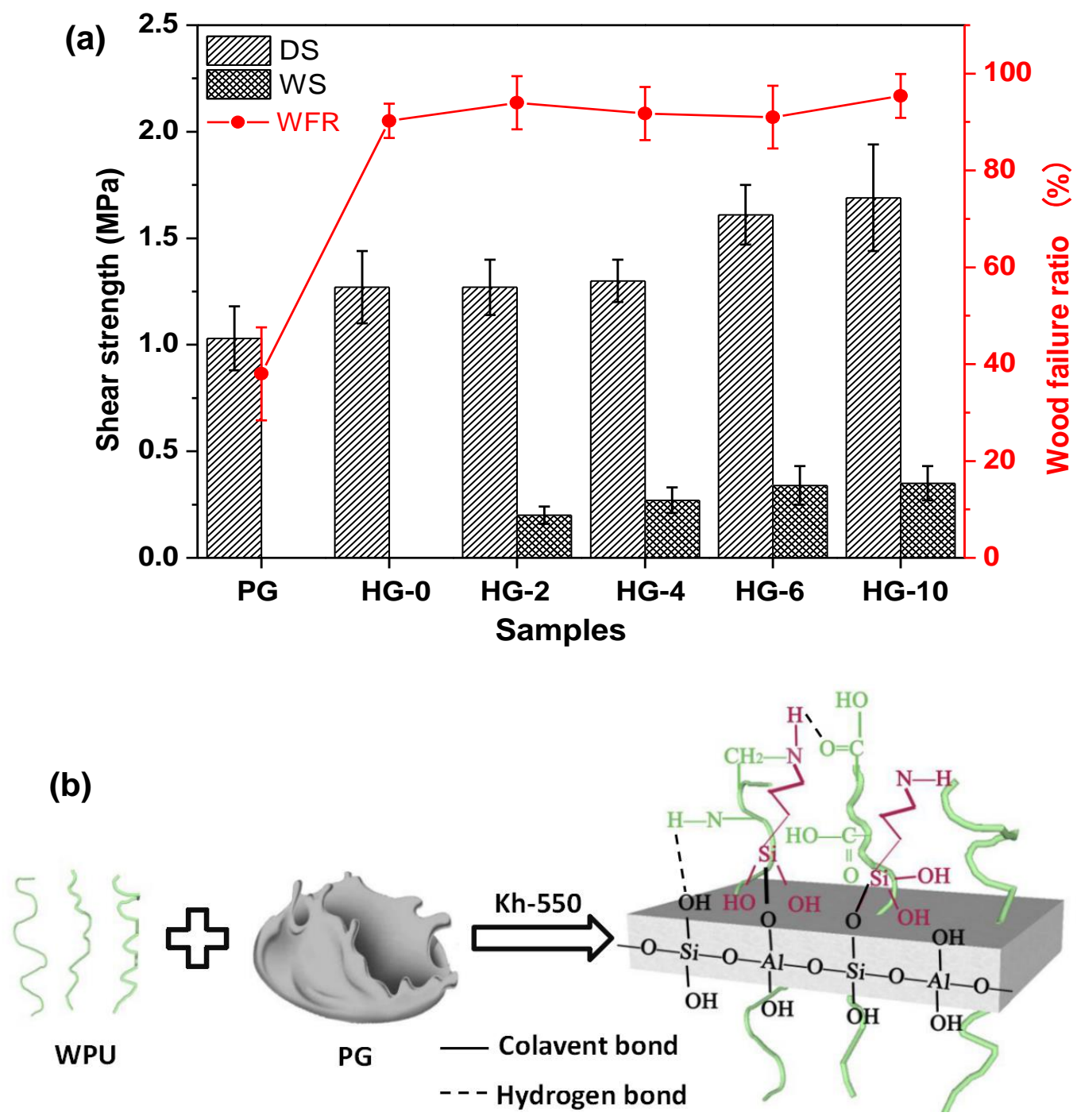

Fig. 7. (a) The dry shear strength (DS), wet shear strength (WS), and wood failure ratio (WFR, curve) in dry geopolymer-based composites with different modifier ratios (b) Enhancement mechanisms of WPU and Kh-550 in geopolymer system 

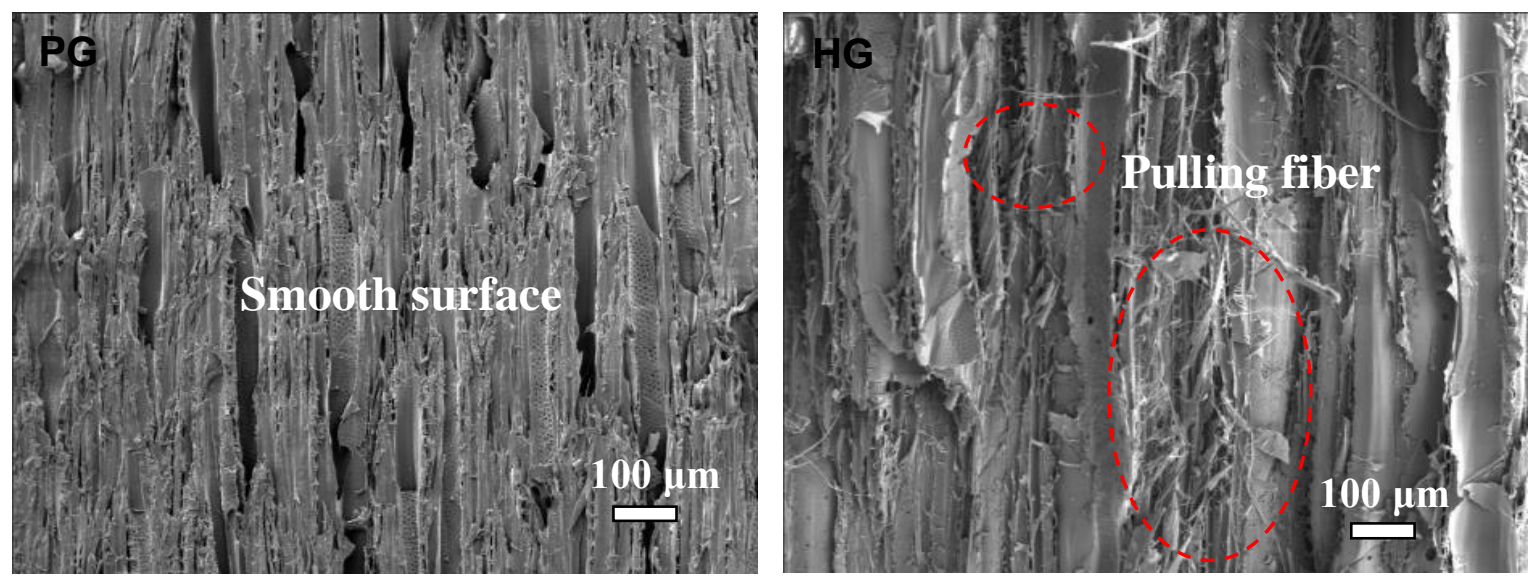

Fig. 8. PG and HG sample SEM wood fracture images after dry shear strength testing

\section{CONCLUSIONS}

1. A simple approach to producing organic-inorganic hybrid geopolymer (HG) was proposed in which waterborne polyurethane (WPU) and silane coupling agent were used as a toughening agent and cross-linking agent, respectively, to enhance the pure geopolymer (PG) matrix. The interfacial structure between geopolymer and wood was evaluated and the potential for application to engineered wood adhesive systems was demonstrated.

2. A distinct mechanical interlocking structure was found in the geopolymer/wood interface, which could be roughly divided into three parts: namely a geopolymer matrix, alkali-wood layer, and wood matrix.

3. The alkali-wood layer notably led to premature structural damage in the shear test.

4. The effects of organic improvement on the shear adhesive strength were investigated, and the results indicated that both the geopolymer-based wood adhesive bonding strength and water resistance were remarkably improved after the introduction of WPU/kh-550.

\section{ACKNOWLEDGMENTS}

The authors are grateful for the support of the National Natural Science Foundation of China, Grant No. 31800485 and Beijing Municipal Excellent Talents Foundation, Grant No. $2017000020124 \mathrm{G} 092$.

\section{REFERENCES CITED}

Alomayri, T. S., Vickers, L., Shaikh, F. U. A., and Low, I. M. (2015). "Mechanical properties of cotton fabric reinforced geopolymer composites at $200-1000^{\circ} \mathrm{C}, " \mathrm{~J} . \mathrm{Adv}$. Ceram. 3(3), 184-193. DOI: 10.1007/s40145-014-0109-x 
Atis, C. D., Görür, E. B., Karahan, O., Bilim, C., Ilkentapar, S., and Luga, E. (2015). "Very high strength (120 MPa) class F fly ash geopolymer mortar activated at different $\mathrm{NaOH}$ amount, heat curing temperature and heat curing duration," Constr. Build. Mater. 96, 673-678. DOI: 10.1016/j.conbuildmat.2015.08.089

Bahrami, M., Shalbafan, A., and Welling, J. (2019). "Development of plywood using geopolymer as binder: Effect of silica fume on the plywood and binder characteristics," Eur. J. Wood. Wood. Prod. 77, 981-994. DOI: 10.1007/s00107-01901462-3

Barbosa, V. F. F., and MacKenzie, K. J. D. (2003). "Thermal behaviour of inorganic geopolymers and composites derived from sodium polysialate," Mater. Res. Bull. 38(2), 319-331. DOI: 10.1016/s0025-5408(02)01022-X

Bell, J. L., Driemeyer, P. E., and Kriven, W. M. (2009). "Formation of ceramics from metakaolin-based geopolymers. Part II: k-Based geopolymer," J. Am. Ceram. Soc. 92(3), 607-615. DOI: 10.1111/j.1551-2916.2008.02922.x

Colangelo, F., Roviello, G., Ricciotti, L., Ferone, C., and Cioffi, R. (2013). "Preparation and characterization of new geopolymer-epoxy resin hybrid mortars," Materials 6(7), 2989-3006. DOI: 10.3390/ma6072989

Du, J., Bu, Y., Shen, Z., Hou, X., and Huang, C. (2016). "Effects of epoxy resin on the mechanical performance and thickening properties of geopolymer cured at low temperature," Mater. Des. 109, 133-145. DOI: 10.1016/j.matdes.2016.07.003

Duan, P., Yan, C., and Luo, W. (2016). "A novel waterproof, fast setting and high early strength repair material derived from metakaolin geopolymer," Constr. Build. Mater. 124, 69-73. DOI: 10.1016/j.conbuildmat.2016.07.058

Duxson, P., Provis, J. L., Lukey, G. C., Mallicoat, S. W., Kriven, W. M., and Van Deventer, J. S. J. (2005). "Understanding the relationship between geopolymer composition, microstructure and mechanical properties," Colloid. Surface. A 269(13), 47-58. DOI: 10.1016/j.colsurfa.2005.06.060

GB/T 17657 (2013). "Test methods of evaluating the properties of wood-based panels and surface decorated wood-based panels," Standardization Administration of China, Beijing, China.

Gharzouni, A., Vidal, L., Essaidi, N., Joussein, E., and Rossignol, S. (2016). "Recycling of geopolymer waste: Influence on geopolymer formation and mechanical properties," Mater. Des. 94, 221-229. DOI: 10.1016/j.matdes.2016.01.043

Ghosh, B., Gogoi, S., Thakur, S., and Karak, N. (2016). "Bio-based waterborne polyurethane/carbon dot nanocomposite as a surface coating material," Prog. Org. Coat. 90, 324-330. DOI: 10.1016/j.porgcoat.2015.10.025

Gouny, F., Fouchal, F., Maillard, P., and Rossignol, S. (2012). "A geopolymer mortar for wood and earth structures," Constr. Build. Mater. 36, 188-195. DOI: 10.1016/j.conbuildmat.2012.04.009

Gu, X., Ma, X., Li, L., Liu, C., Cheng, K., and Li, Z. (2013). "Pyrolysis of poplar wood sawdust by TG-FTIR and Py-GC/MS,” J. Anal Appl Pyrol. 102, 16-23. DOI: 10.1016/j.jaap.2013.04.009

Imai, Y., Itoh, H., Naka, K., and Chujo, Y. (2000). "Thermally reversible IPN organicinorganic polymer hybrids utilizing the Diels-Alder reaction," Macromolecules 33(12), 4343-4346. DOI: 10.1021/ma991899b

Kroehong, W., Jaturapitakkul, C., Pothisiri, T., and Chindaprasirt, P. (2018). "Effect of oil palm fiber content on the physical and mechanical properties and microstructure 
of high-calcium fly ash geopolymer paste," Arab. J. Sci. Eng. 43, 5215-5224. DOI: 10.1007/s13369-017-3059-0

Kuan, H.-C., Ma, C -C. M., Chang, W.-P., Yuen, S.-M., Wu, H.-H., and Lee, T.-M. (2005). "Synthesis, thermal, mechanical and rheological properties of multiwall carbon nanotube/waterborne polyurethane nanocomposite," Compos. Sci. Technol. 65(11-12), 1703-1710. DOI: 10.1016/j.compscitech.2005.02.017

Latella, B. A., Perera, D. S., Escott, T. R., and Cassidy, D. J. (2006). "Adhesion of glass to steel using a geopolymer," J. Mater. Sci. 41(4), 1261-1264. DOI: 10.1007/s10853005-4234-3

Law, D. W., Adam, A. A., Molyneaux, T. K., Patnaikuni, I., and Wardhono, A. (2015). "Long term durability properties of class F fly ash geopolymer concrete," Mater. Struct. 48(3), 721-731. DOI: 10.1617/s11527-014-0268-9

Lee, D. I., Kim, S. H., and Lee, D. S. (2019). "Synthesis of self-healing waterborne polyurethane systems chain extended with chitosan," Polymers 11(3), Article number 503. DOI: $10.3390 /$ polym 11030503

Lehto, J., Louhelainen, J., Kłosińska, T., Drożdżek, M., and Alén, R. (2018). "Characterization of alkali-extracted wood by FTIR-ATR spectroscopy," Biomass. Convers. Bior. 8, 847-855. DOI: 10.1007/s13399-018-0327-5

Le Troëdec, M., Peyratout, C. S., Smith, A., and Chotard, T. (2009). "Influence of various chemical treatments on the interactions between hemp fibres and a lime matrix," J. Eur. Ceram. Soc. 29(10), 1861-1868. DOI: 10.1016/j.jeurceramsoc.2008.11.016

Li, Z., Chen, R., and Zhang, L. (2013). "Utilization of chitosan biopolymer to enhance fly ash-based geopolymer," J. Mater. Sci. 48(22), 7986-7993. DOI: 10.1007/s10853-0137610-4

Mucsi, G., Szabó, R., Nagy, S., Bohács, K., Gombköto, I., and Debreczeni, Á. (2017). "Development of polystyrene-geopolymer composite for thermal insulating material and its properties with special regards to flame resistance," in: $3^{\text {rd }}$ International Conference on Innovative Materials, Structures, and Technologies, Riga, Latvia, pp. 1-8.

Mucsi, G., Szenczi, Á., and Nagy, S. (2018). "Fiber reinforced geopolymer from synergetic utilization of fly ash and waste tire," J. Clean. Prod. 178, 429-440. DOI: 10.1016/j.jclepro.2018.01.018

Nematollahi, B., Sanjayan, J., and Shaikh, F. U. A. (2015). "Tensile strain hardening behavior of PVA fiber-reinforced engineered geopolymer composite," J. Mater. Civil. Eng. 27(10), Article ID 04015001. DOI: 10.1061/(asce)mt.1943-5533.0001242

Pasupathy, K., Berndt, M., Sanjayan, J., Rajeev, P., and Cheema, D. S. (2017). "Durability of low calcium fly ash based geopolymer concrete culvert in a saline environment," Cement. Concrete. Res. 100, 297-310. DOI: 10.1016/j.cemconres.2017.07.010

Sarmin, S. N., Welling, J., Krause, A., and Shalbafan, A. (2014). "Investigating the possibility of geopolymer to produce inorganic-bonded wood composites for multifunctional construction material - a review," BioResources 9(4), 7941-7950. DOI: 10.15376/biores.9.4.Sarmin

Sá Ribeiro, R. A., Sá Ribeiro, M. G., Sankar, K., and Kriven, W. M. (2016). "Geopolymer-bamboo composite - A novel sustainable construction material," Constr. Build. Mater. 123, 501-507. DOI: 10.1016/j.conbuildmat.2016.07.037 
Sethi, J., Illikainen, M., Sain, M., and Oksman, K. (2017). "Polylactic acid/polyurethane blend reinforced with cellulose nanocrystals with semi-interpenetrating polymer network (S-IPN) structure," Eur. Polym. J. 86, 188-199. DOI: 10.1016/j.eurpolymj.2016.11.031

Shalbafan, A., Welling, J., and Hasch, J. (2016). "Geopolymers as potential new binder class for the wood based composite industry," Holzforschung 70(8), 755-761. DOI: 10.1515/hf-2015-0206

Shalbafan, A., Welling, J., and Hasch, J. (2017). "Effect of aluminosilicate powders on the applicability of innovative geopolymer binders for wood-based composites," Eur. J. Wood. Wood. Prod. 75(6), 893-902. DOI: 10.1007/s00107-017-1172-0

Wang, N., and Zhang, L. (2004). "Preparation and characterization of soy protein plastics plasticized with waterborne polyurethane," Polym. Int. 54(1), 233-239. DOI: 10.1002/pi.1696

Wang, X., Xing, W., Song, L., Yang, H., Hu, Y., and Yeoh, G. H. (2012). "Fabrication and characterization of graphene-reinforced waterborne polyurethane nanocomposite coatings by the sol-gel method," Surf. Coat. Tech. 206(23), 4778-4784. DOI: 10.1016/j.surfcoat.2012.03.077

Wen, C., Lu, L., and Li, X. (2014). "Mechanically robust gelatin-alginate IPN hydrogels by a combination of enzymatic and ionic crosslinking approaches," Macromol. Mater. Eng. 299(4), 504-513. DOI: 10.1002/mame.201300274

Ye, H., Zhang, Y., Yu, Z., and Mu, J. (2018). "Effects of cellulose, hemicellulose, and lignin on the morphology and mechanical properties of metakaolin-based geopolymer," Constr. Build. Mater. 173, 10-16. DOI: 10.1016/j.conbuildmat.2018.04.028

Zhang, Z., Provis, J. L., Reid, A., and Wang, H. (2014). "Geopolymer foam concrete: An emerging material for sustainable construction," Constr. Build. Mater. 56, 113-127. DOI: 10.1016/j.conbuildmat.2014.01.081

Zhang, Z., Provis, J. L., Reid, A., and Wang, H. (2015). "Mechanical, thermal insulation, thermal resistance and acoustic absorption properties of geopolymer foam concrete," Cement. Concrete. Compos. 62, 97-105. DOI: 10.1016/j.cemconcomp.2015.03.013

Article submitted: May 5, 2020; Peer review completed: June 21, 2020; Revised version received and accepted: August 14, 2020; Published: August 19, 2020.

DOI: $10.15376 /$ biores.15.4.7573-7585 